\title{
Improved Visible-light Photocatalytic Activity of Bi-crystalline Mesoporous Ti- tania Codoped with Carbon and Silver
}

\author{
LU Qiang ${ }^{1}$, ZHANG Zhi-Bo ${ }^{1}$, DONG Chang-Qing ${ }^{1}$, ZHANG Xiao-Yuan ${ }^{2}$, CUI Fang-Ming ${ }^{2}$
}

(1. National Engineering Laboratory for Biomass Power Generation Equipment, North China Electric Power University, Beijing 102206, China; 2. Qian Xuesen Laboratory of Space Technology, Chinese Academy of Space Technology, Beijing 100094, China)

\begin{abstract}
A bi-crystalline mesoporous titania $\left(\right.$ meso- $\left.\mathrm{TiO}_{2}\right)$ with anatase and rutile composite nanocrystal frameworks was prepared and then modified by carbon doping $\left(\mathrm{C}-\mathrm{meso}-\mathrm{TiO}_{2}\right)$, silver nanoparticle loading $\left(\mathrm{Ag}-\mathrm{meso}^{-} \mathrm{TiO}_{2}\right)$, and carbon-silver codoping (Ag-C-meso- $\mathrm{TiO}_{2}$ ). The visible-light photocatalytic activities of the samples were evaluated by the degeneration of aqueous methylene blue (MB) solution under visible-light irradiation (wavelength $>420 \mathrm{~nm}$ ). The prepared bi-crystalline mesoporous samples showed obviously higher visible-light photocatalytic activity than that of the commercial anatase titania nanoparticles (NPs). Ag-C-meso- $\mathrm{TiO}_{2}$ exhibited the highest visible-light photocatalytic activity which could be attributed to the band gap narrowed by the doped carbon and the plasmon electron transfer from Ag NPs to the titania matrix, and the corresponding MB degeneration rate reached $65 \%$ after 180 min visible-light irradiation while that of the commercial titania NPs just reached 7\%.
\end{abstract}

Key words: visible-light; photocatalytic activity; bi-crystalline; mesoporous titania; silver; carbon

Titania is an important semiconductor for photocatalytic application and regarded as the environmentally sustainable photocatalyst. However, it only exhibits photocatalytic activity under UV light due to the large band gap energy of $3.2 \mathrm{eV}$. Most of the sun energy reached the earth is concentrated in visible-light region. In order to efficiently utilize the solar energy, many research efforts have been paid to the visible-light photocatalysis of titania $^{[1-3]}$. One promising method is to narrow the band gap energy of the titania ${ }^{[4-8]}$ by element doping, such as nitrogen $^{[1]}$, carbon $^{[5]}$, iodine ${ }^{[7]}$ and so on. Carbon doped titania have been reported to show smaller band gap energy of $2.32 \mathrm{eV}$ and improved visible absorption ${ }^{[4]}$. Silver NP loaded titania can improve the photocatalytic activity since the silver NPs can effectively separate the photogenerated electron-hole pairs and decrease their recombination rate ${ }^{[9]}$. When carbon and silver codoping is adapted, the dopants can not only narrow the band gap energy but also improve the visible-light absorption of titania ${ }^{[9]}$.

Meso- $\mathrm{TiO}_{2}$ is an interesting material for photocatalytic application due to its high surface area and continuous framework compared with the separated individual $\mathrm{NPs}^{[8]}$. Currently, many research efforts have been done to improve the photocatalytic activity of the mesoporous $\operatorname{titania}^{[10-14]}$.

Most of the research attentions are concentrated on the photocatalytic activity of the anatase titania. Recent reports showed that the composites with two kinds of semiconductors or two phases of the same semiconductor were beneficial for impeding the recombination of the photogenerated electron-hole pairs and thus enhanced the photocatalytic activity ${ }^{[15]}$.

The visible-light photocatalysis of meso- $\mathrm{TiO}_{2}$ with anatase and rutile bi-crystalline frameworks has not been investigated very well until now, except for the report ${ }^{[16]}$ where the influence of inorganic precursor on the phase composition of the meso- $\mathrm{TiO}_{2}$ frameworks was investigated.

Herein we prepared a bi-crystalline meso- $\mathrm{TiO}_{2}$ with anatase and rutile composite frameworks and further modified with carbon and silver NPs. We investigated the visible-light photocatalytic activity of the samples by the degradation of the aqueous methylene blue (MB) solution under visible-light irradiation (wavelength $>420 \mathrm{~nm}$ ). The results showed that the bi-crystalline meso- $\mathrm{TiO}_{2}$ samples presented obviously higher visible-light photocatalytic activity than that of the commercial anatase NPs. And the carbon-silver codoped bi-crystalline meso- $\mathrm{TiO}_{2}$ exhibited

Received date: 2014-07-07; Modified date: 2014-09-13; Published online: 2014-09-28

Foundation item: National Natural Science Foundation of China (51202288); National Torch Program (2013GH561645); Fundamental Research Funds for the Central Universities (2014ZD17)

Biography: LU Qiang(1982-), male, associate professor. E-mail: qianglu@mail.ustc.edu.cn

Corresponding author: CUI Fang-Ming, associate professor. E-mail: cfm@mail.ustc.edu.cn 
the highest visible-light photocatalytic activity.

\section{Experimental}

\subsection{Sample preparation}

The commercial anatase NPs with particle diameter of 5-10 nm were purchased from Aladdin.

The blank bi-crystalline meso- $\mathrm{TiO}_{2}$ powder was prepared according to the report ${ }^{[17]}$. A post thermal treatment was adapted. The prepared meso- $\mathrm{TiO}_{2}$ was firstly calcined at $350^{\circ} \mathrm{C}$ for $5 \mathrm{~h}$ under $\mathrm{N}_{2}$ atmosphere and then kept at $350^{\circ} \mathrm{C}$ for $2 \mathrm{~h}$ in air.

The carbon doped meso- $\mathrm{TiO}_{2}$ sample $\left(\mathrm{C}\right.$-meso- $\left.\mathrm{TiO}_{2}\right)$ was prepared as follows. Firstly, the new prepared meso$\mathrm{TiO}_{2}$ powder and glucose were dropped and dissolved into deionic water with stirring until the water evaporated. Then the remains were collected and calcined under $\mathrm{N}_{2}$ at $350^{\circ} \mathrm{C}$ for $5 \mathrm{~h}$ and then kept at $350^{\circ} \mathrm{C}$ for $2 \mathrm{~h}$ in air, to obtain the $\mathrm{C}$-meso- $\mathrm{TiO}_{2}$.

The silver NPs loaded meso- $\mathrm{TiO}_{2}$ sample (Ag-meso$\mathrm{TiO}_{2}$ ) was prepared as follows. Firstly, the template removed meso- $\mathrm{TiO}_{2}$ powder and $\mathrm{AgNO}_{3}$ were dropped into deionic water with stirring for $30 \mathrm{~min}$. Secondly, appropriate amount of urea was dissolved into the above solution to deposit $\mathrm{Ag}^{+}$onto the titania surface. Several minutes later, the mixture was transferred to $50^{\circ} \mathrm{C}$ water bath and stirred for $30 \mathrm{~min}$. Afterwards, the mixture was filtered and dried in a vacuum oven, and finally calcined at $200^{\circ} \mathrm{C}$ for $2 \mathrm{~h}$ in $\mathrm{H}_{2} / \mathrm{Ar}$ atmosphere to obtain the Ag-meso- $\mathrm{TiO}_{2}$.

The carbon-silver codoped meso- $\mathrm{TiO}_{2}$ sample (Ag-Cmeso- $\mathrm{TiO}_{2}$ ) was prepared in the similar way of the Agmeso- $\mathrm{TiO}_{2}$, with the only difference of using the C-meso$\mathrm{TiO}_{2}$ to replace the meso- $\mathrm{TiO}_{2}$.

\subsection{Characterization}

Small-angle (SAXRD) and wide-angle X-ray diffraction (WAXRD) were used to characterize the samples with Rigaku Rotaflex diffractometer using $\mathrm{Cu} \mathrm{K \alpha}$ radiation. Transmission electron microscope (TEM) and simultaneous energy-dispersive spectroscope (EDS) were used to analyze the microstructure and the elements using JEOL $2100 \mathrm{~F}$ electron microscope operating at $200 \mathrm{kV} . \mathrm{N}_{2}$ adsorption-desorption isotherms were measured at $77 \mathrm{~K}$ with a Micromeritics Tristar 3000 analyzer. The Brunauer-Emmett-Teller (BET) method was used to calculate the surface areas. And the pore size distribution was derived from the adsorption branches of the isotherms by using Barrett-Joyner-Halenda (BJH) model. UV-visible absorption spectra were measured on Shimadzu UV-3101 spectrometer.

\subsection{Visible-light photocatalysis}

The visible-light photocatalytic activities of the samples were evaluated by the degradation of aqueous $\mathrm{MB}$ solution. A $50 \mathrm{~W}$ Xe lamp (CEL-HXF300) was used as visible-light source. The samples were tested under the irradiation with the wavelength above $420 \mathrm{~nm}$. The concentration of the aqueous $\mathrm{MB}$ solution was around $1.0 \times 10^{-5} \mathrm{~mol} / \mathrm{L}$. The photocatalyst amount was chosen to be $5 \mathrm{~g} / \mathrm{L}$. Typically, $0.3 \mathrm{~g}$ photocatalyst was dropped into $60 \mathrm{~mL}$ aqueous $\mathrm{MB}$ solution followed by $30 \mathrm{~min}$ stirring and ultrasonic treatment under dark in order to reach absorption equilibrium between photocatalyst and MB. Then the $\mathrm{MB}$ concentration after the absorption equilibrium was denoted as $C_{0}$. The MB concentration with the visiblelight irradiation was denoted as $C$ and monitored by a UV-2000 Spectrometer.

\section{Results and discussion}

Figure 1 shows the SAXRD pattern of the bi-crystalline meso- $\mathrm{TiO}_{2}$ after calcination $\left(350^{\circ} \mathrm{C}\right.$ for $5 \mathrm{~h}$ in $\mathrm{N}_{2}$ and then $350^{\circ} \mathrm{C}$ for $2 \mathrm{~h}$ in air), which has two diffraction peaks that could be indexed as (100) and (110) plane diffractions of the two-dimensional hexagonal meso-structure $^{[17]}$. The latter diffraction peak is not distinct, which might be due to the partial collapse of the ordered mesoporous channels after calcination. The hexagonal mesostructure of the sample could be further confirmed by the next TEM results.

Figure 2 gives the TEM image and EDS spectrum of the bi-crystalline Ag-C-meso- $\mathrm{TiO}_{2}$. The ordered 2dimensional hexagonal mesoporous channels could be clearly seen in the TEM image, which is consistent with the above SAXRD result. The average diameter of the mesoporous channels is estimated to be $5.5 \mathrm{~nm}$ from Fig. 2(a). The EDS spectrum presents obvious $\mathrm{C}, \mathrm{O}$

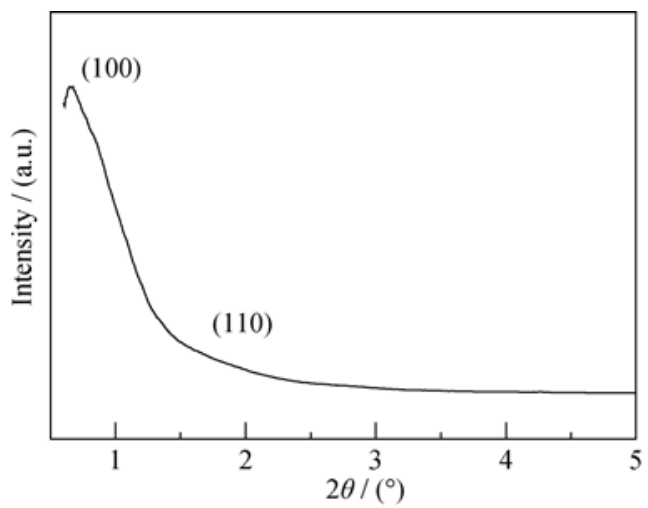

Fig. 1 SAXRD pattern of the bi-crystalline meso- $\mathrm{TiO}_{2}$ after calcination 

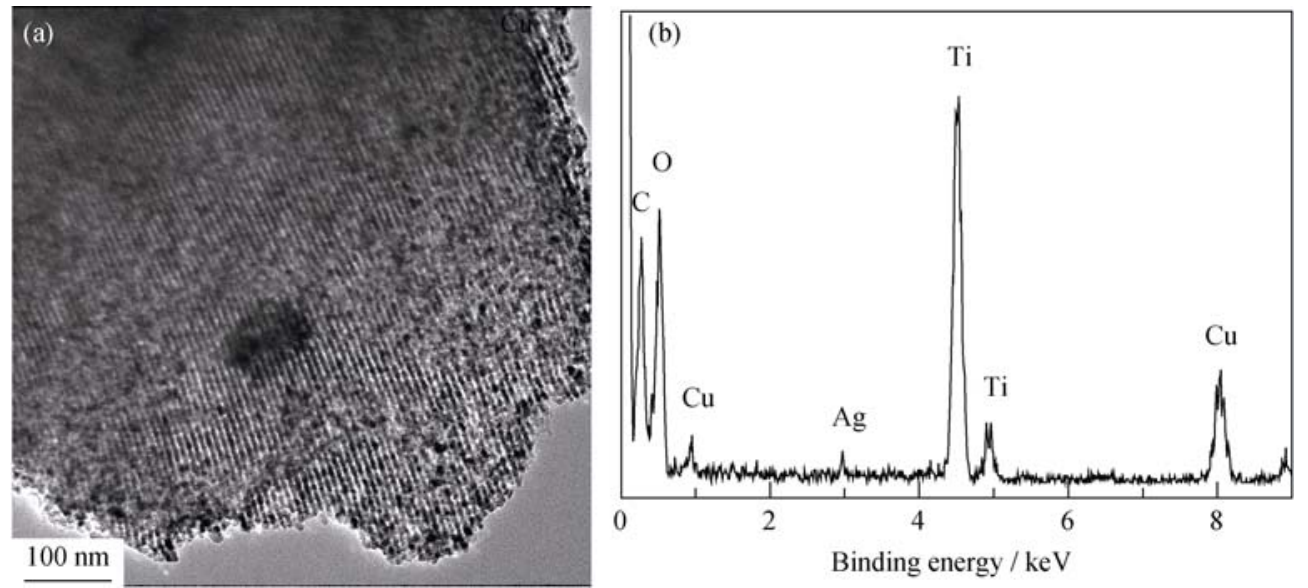

Fig. 2 TEM image (a) and EDS spectrum (b) of the bi-crystalline Ag-C-meso- $\mathrm{TiO}_{2}$

and Ti signals but weak Ag signal. This confirms the existence of the $\mathrm{Ag}$, $\mathrm{Ti}$ and $\mathrm{O}$ elements in Ag-C-meso$\mathrm{TiO}_{2}$ sample, but it is hard to ensure the existence of carbon in the sample due to the sample support copper mesh containing carbon thin films. The Ag NPs could hardly be observed in the TEM image because of the small particle size and low amount of the Ag NPs, as the weak peak intensity of Ag element seen in the EDS spectrum. The low Ag content of the sample could avoid the Ag NPs aggregation or growth, which would decrease the photocatalytic efficiency ${ }^{[18]}$.

Figure 3 shows the WAXRD patterns of the blank bi-crystalline meso- $\mathrm{TiO}_{2}$ and $\mathrm{Ag}-\mathrm{C}$-meso- $\mathrm{TiO}_{2}$. Both patterns display the diffractions of rutile and anatase phases, indicating that the titania frameworks of the two samples are composed of rutile and anatase. The bi-crystalline titania frameworks might be resulted by the composite inorganic precursors of titanium tetrachloride and titanium isopropoxide. Because a certain amount of $\mathrm{HCl}$ and/or $\mathrm{Cl}^{-}$could favour the growth of rutile nucleus due to their weak steric effect on the $\mathrm{TiO}_{6}{ }^{2-}$ octahedron under acidic conditions ${ }^{[16]}$. The anatase percentage $(A \%)$

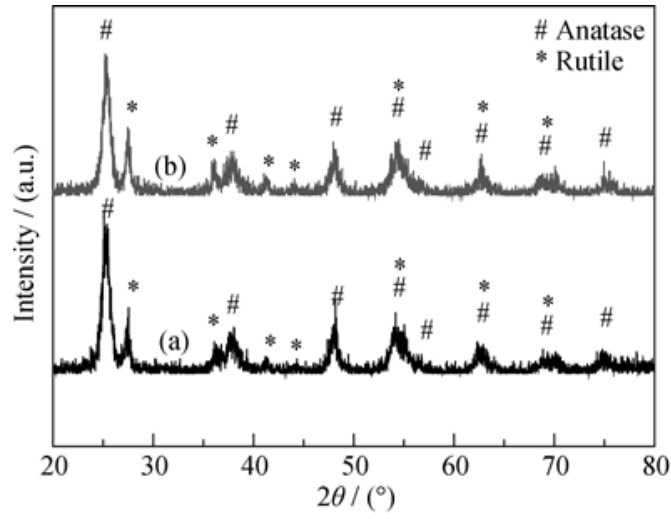

Fig. 3 WAXRD patterns of bi-crystalline meso- $\mathrm{TiO}_{2}$ (a) and Ag-C-meso- $\mathrm{TiO}_{2}(\mathrm{~b})$ of the bi-crystalline frameworks could be estimated from the integrated intensity of the diffraction peaks at $2 \theta=25.3^{\circ}$ for anatase and $2 \theta=27.4^{\circ}$ for rutile by the following equation $^{[16]}$.

$$
A(\%)=100 /\left(1+1.265 I_{\mathrm{r}} / I_{\mathrm{a}}\right)
$$

Where $I_{\mathrm{r}}$ and $I_{\mathrm{a}}$ are the peak intensities of rutile at $2 \theta=27.4^{\circ}$ and anatase at $2 \theta=25.3^{\circ}$, respectively. The anatase percentages are calculated to be $51.2 \%$ and $74.2 \%$ for the blank meso- $\mathrm{TiO}_{2}$ and $\mathrm{Ag}-\mathrm{C}$-meso $\mathrm{TiO}_{2}$.

Figure 4 shows the $\mathrm{N}_{2}$ adsorption-desorption isotherms of bi-crystalline meso- $\mathrm{TiO}_{2}$ and Ag-C-meso $\mathrm{TiO}_{2}$, which exhibit a type IV curve with a steep rise in adsorption region at $0.5-0.8$ relative pressure $\left(P / P_{0}\right)$ implying an uniform cylindrical pore geometry. The pore size distribution of meso- $\mathrm{TiO}_{2}$ is shown in the inset in Fig. 4. The average pore size of meso- $\mathrm{TiO}_{2}$ is calculated to be $5.3 \mathrm{~nm}$ from the $\mathrm{BJH}$ adsorption data, which is consistent with the above TEM result. The surface areas are calculated to be 123.5 and $95.9 \mathrm{~m}^{2} / \mathrm{g}$ for meso- $\mathrm{TiO}_{2}$ and $\mathrm{Ag}$-C-meso $\mathrm{TiO}_{2}$ by BET method.

Figure 5 gives the UV-visible adsorption spectra of

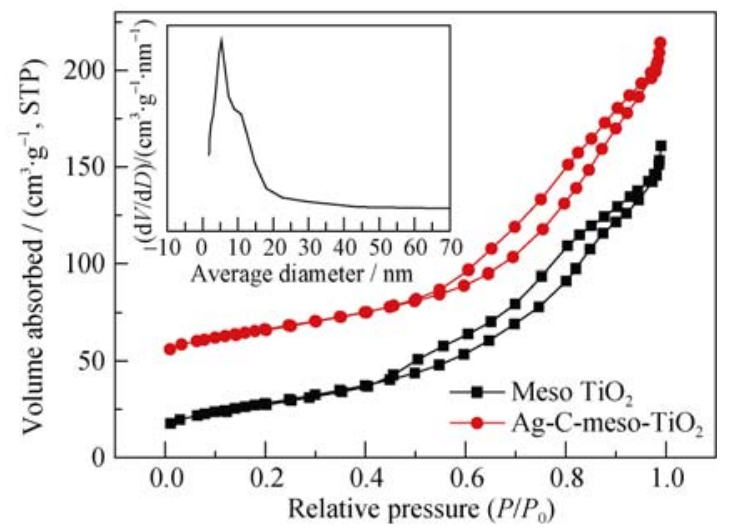

Fig. $4 \mathrm{~N}_{2}$ adsorption-desorption isotherms of the bi-crystalline meso- $\mathrm{TiO}_{2}$ and Ag-C-meso- $\mathrm{TiO}_{2}$

The inset is the pore size distribution of the blank meso- $-\mathrm{TiO}_{2}$ 


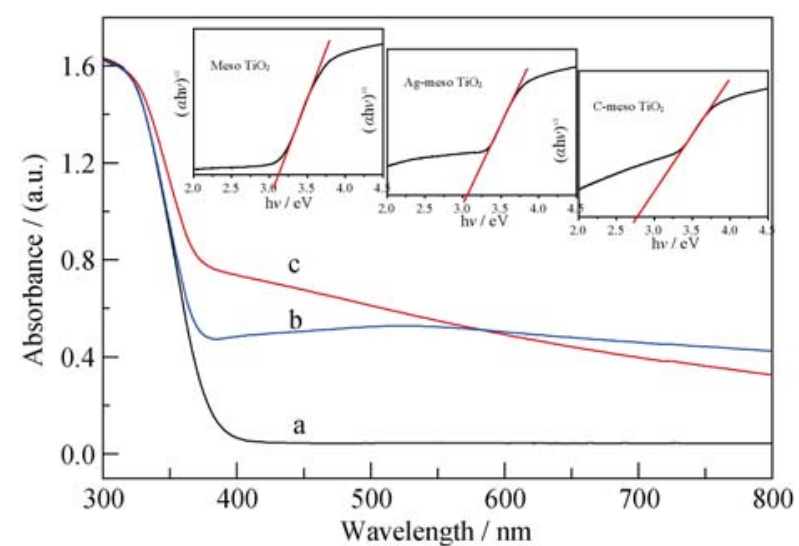

Fig. 5 UV-visible adsorption spectra of (a) the blank bi-crystalline meso- $\mathrm{TiO}_{2}$, (b) Ag-meso- $\mathrm{TiO}_{2}$ and (c) C-meso- $\mathrm{TiO}_{2}$

The insets are the curves of $(\alpha h v)^{1 / 2}$ against $h v$ of the samples

the bi-crystalline meso- $\mathrm{TiO}_{2}$. The bi-crystalline meso- $\mathrm{TiO}_{2}$ does not show any absorption at visible region from $380 \mathrm{~nm}$ to $800 \mathrm{~nm}$. In contrast, $\mathrm{Ag}$-meso- $\mathrm{TiO}_{2}$ presents improved visible-light absorption with a broad absorption peak at around $520 \mathrm{~nm}$, which is corresponded to the surface plasmon resonance (SPR) absorption of the loaded Ag $\mathrm{NPs}^{[19]}$. The semiconductor absorption edge of Ag-meso$\mathrm{TiO}_{2}$ did not change greatly, still at around $350 \mathrm{~nm}$. C-meso- $\mathrm{TiO}_{2}$ also presents strong absorption in visible region, which could be attributed to some carbon coatings on the surface of the titania matrix. Meanwhile the absorption edge of C-meso- $\mathrm{TiO}_{2}$ moves toward the higher wavelength at around $360 \mathrm{~nm}$, which could be attributed to the doped carbon within the titania lattice. The band gap energy of the samples are estimated from the intercept of the linear fitting in the plots of $(\alpha \mathrm{h} v)^{1 / 2}$ against h $v$, where $\alpha$ and $\mathrm{h} v$ are the absorption coefficient and photon energy ${ }^{[5]}$. The fitting results of the band gap energy are 3.12, 3.05 and $2.77 \mathrm{eV}$ for sample meso- $\mathrm{TiO}_{2}$, Ag-meso- $\mathrm{TiO}_{2}$ and C-meso- $\mathrm{TiO}_{2}$, as shown in the insets in Fig. 5. The band gap energy of C-meso- $-\mathrm{TiO}_{2}$ is obviously smaller than the others.

Figure 6 shows the visible-light photocatalysis results of the samples. When the commercial anatase NPs with diameter of 5-10 nm were used, the MB concentration did not vary too much and just slightly decreased after $180 \mathrm{~min}$ visible-light irradiation. In comparison, the bi-crystalline mesoporous samples show obvious visible-light photocatalytic activities indicated by the dramatic decrease of MB concentration after irradiation.

When the bi-crystalline meso- $\mathrm{TiO}_{2}$ is used, upon the visible-light irradiation starts, the $\mathrm{MB}$ concentration distinctly decreases. The corresponding $C / C_{0}$ reaches 0.45 after 180 min irradiation. The carbon doped sample Cmeso- $\mathrm{TiO}_{2}$ presents nearly the same $\mathrm{MB}$ degradation rate. This result indicates that carbon doping in meso- $\mathrm{TiO}_{2}$ is

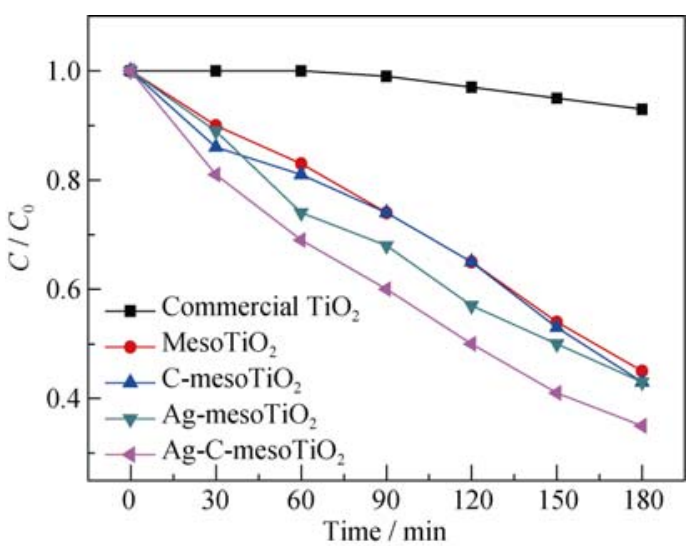

Fig. 6 Visible-light photodegradation of aqueous MB solution by different titania samples. The data in the graph are averaged by five points and the offsets are less than $7 \%$ of the averaged data

not necessary for improving the visible-light photocatalytic activity although the band gap of the C-meso $\mathrm{TiO}_{2}$ is narrowed. The Ag NPs loaded sample Ag-meso- $\mathrm{TiO}_{2}$ shows an improved photocatalytic activity compared with that of the blank meso- $\mathrm{TiO}_{2}$ sample. Furthermore, the carbon-silver codoped sample Ag-C-meso- $\mathrm{TiO}_{2}$ presents a more improved photocatalytic activity compared with those of the single element doped samples C-meso- $\mathrm{TiO}_{2}$ and $\mathrm{Ag}$-meso- $\mathrm{TiO}_{2}$, and the corresponding $C / C_{0}$ reaches 0.35 after $180 \mathrm{~min}$ irradiation. These results indicate the visible-light photocatalytic activity of the bi-crystalline meso- $\mathrm{TiO}_{2}$ could be further improved by carbon-silver codoping.

The band gap narrowing of the titania matrix by carbon doping has been demonstrated by the result in Fig. 5 and other report ${ }^{[4]}$. This band gap narrowing effect could improve the visible-light absorption of the sample Cmeso- $\mathrm{TiO}_{2}$ as curve (c) seen in Fig. 5, but without improved visible-light photocatalytic activity compared with that of the undoped sample meso- $\mathrm{TiO}_{2}$. However, the $\mathrm{Ag}$ NP loading on meso- $\mathrm{TiO}_{2}$ could improve the visible-light photocatalytic activity compared with that of meso- $\mathrm{TiO}_{2}$. Meanwhile the photocatalytic activity of Ag-C-mesoTiO is further improved compared with that of Ag-meso- $\mathrm{TiO}_{2}$. Therefore we inferred that Ag NPs would supply or increase an apparent surface charge carriers ${ }^{[20]}$.

When the photocatalysis processed under visiblelight, the matrix of Ag-meso- $\mathrm{TiO}_{2}$ could not generate sufficient photogenerated electrons and holes. In addition, titania was known as a good electron-accepting metal oxide through many transient absorption experiments, probably due to its high state density. Therefore, the electrons resulted by the SPR of Ag NPs under visible-light could transfer to the meso- $\mathrm{TiO}_{2}$ matrix and therefore enhance the photocatalytic activity of the Ag-meso- $\mathrm{TiO}_{2}$ and 
Ag-C-meso- $\mathrm{TiO}_{2}{ }^{[21-22]}$.

\section{Conclusions}

In summary, a bi-crystalline meso- $\mathrm{TiO}_{2}$ with anatase and rutile composite frameworks was prepared and further modified with carbon-silver codoping. The visible-light photocatalytic activities of the samples were investigated by the degradation of aqueous MB solution. The prepared bi-crystalline mesoporous samples showed obviously improved visible-light photocatalytic activity, which could be attributed to the bi-crystalline frameworks and their high surface areas. The carbon-silver codoped sample Ag-Cmeso- $\mathrm{TiO}_{2}$ presented the highest visible-light photocatalytic activity, which could be attributed to the band gap narrowing by carbon doping and the SPR electron transfer from Ag NPs to the titania matrix.

\section{References:}

[1] ASAHI R, MORIKAWA T, OHWAKI T, et al. Visible-light photocatalysis in nitrogen-doped titanium oxides. Science, 2001, 293(5228): 269-271.

[2] WANG E J, HE T, ZHAO L S, et al. Improved visible light photocatalytic activity of titania doped with tin and nitrogen. $J$. Mater. Chem., 2011, 21(1): 144-150.

[3] CHEN C C, MA W H, ZHAO J C. Semiconductor-mediated photodegradation of pollutants under visible-light irradiation. Chem. Soc. Rev., 2010, 39(11): 4206-4219.

[4] SHAHED U M K, MOFAREH A, WILLIAM B I. Efficient photochemical water splitting by a chemically modified n-TiO ${ }_{2}$. Science, 2002, 297(5590): 2243-2245.

[5] ZHANG Y, ZHANG P, HUO Y N, et al. Ethanol supercritical route for fabricating bimodal carbon modified mesoporous $\mathrm{TiO}_{2}$ with enhanced photocatalytic capability in degrading phenol. Appl. Catal. B, 2012, 115-116(5): 236-244.

[6] CHEN X B, LIU L, YU P Y, et al. Increasing solar absorption for photocatalysis with black hydrogenated titanium dioxide nanocrystals. Science, 2011, 331(6018): 746-750.

[7] HONG X T, WANG Z P, CAI W M, et al. Visible-light-activated nanoparticle photocatalyst of iodine-doped titanium dioxide. Chem. Mater., 2005, 17(6): 1548-1552.

[8] ISMAIL A A, BAHNEMANN D W. Mesoporous titania photocatalysts: preparation, characterization and reaction mechanisms. $J$. Mater. Chem., 2011, 21(32): 11686-11707.

[9] ZHANG P, SHAO C, ZHANG Z, et al. Core/shell nanofibers of $\mathrm{TiO}_{2} @$ carbon embedded by Ag nanoparticles with enhanced visible photocatalytic activity. J. Mater. Chem., 2011, 21(44): 17746-17753.

[10] FANG J, WANG F, QIAN K, et al. Bifunctional N-doped mesoporous $\mathrm{TiO}_{2}$ photocatalysts. J. Phys. Chem. C, 2008, 112(46): $18150-18156$.

[11] HUANG Y, Ho W K, LEE S, et al. Effect of carbon doping on the mesoporous structure of nanocrystalline titanium dioxide and its solar-light-driven photocatalytic degradation of $\mathrm{NO}_{x}$. Langmuir, 2008, 24(7): 3510-3516.

[12] LIU R L, REN Y J, SHI Y F, et al. Controlled synthesis of ordered mesoporous $\mathrm{C}-\mathrm{TiO}_{2}$ nanocomposites with crystalline titania frameworks from organic-inorganic-amphiphilic coassembly. Chem. Mater., 2008, 20(3): 1140-1146.

[13] ISMAIL A A, BAHNEMANN D W, BANNAT I, et al. Gold nanoparticles on mesoporous interparticle networks of titanium dioxide nanocrystals for enhanced photonic efficiencies. J. Phys. Chem. C, 2009, 113(17): 7429-7435.

[14] ANDERSSON M, BIRKEDAL H, FRANKLIN N R, et al. $\mathrm{Ag} / \mathrm{AgCl}$-loaded ordered mesoporous anatase for photocatalysis. Chem. Mater., 2005, 17(6): 1409-1415.

[15] YU J C, JIA G, WING K, et al. Effects of F-doping on the photocatalytic activity and microstructures of nanocrystalline $\mathrm{TiO}_{2}$ powders. Chem. Mater., 2002, 14(9): 3808-3816.

[16] CHEN L, YAO B D, CAO Y, et al. Synthesis of well-ordered mesoporous titania with tunable phase content and high photoactivity. J. Phys. Chem. C, 2007, 111(32): 1184911853.

[17] TIAN B Z, YANG H F, LIU X Y, et al. Fast preparation of highly ordered nonsiliceous mesoporous materials via mixed inorganic precursors. Chem. Commun., 2002(17): 1824-1825.

[18] YANG X, WANG Y H, XU L L, et al. Silver and indium oxide codoped $\mathrm{TiO}_{2}$ nanocomposites with enhanced photocatalytic activity. J. Phys. Chem. C, 2008, 112(30): 11481-11489.

[19] EVANOFF D D, CHUMANOV G. Synthesis and optical properties of silver nanoparticles and arrays. ChemPhysChem, 2005, 6(7): 1221-1231.

[20] LIU G, ZHAO Y N, SUN C H, et al. Synergistic effects of B/N doping on the visible-light photocatalytic activity of mesoporous $\mathrm{TiO}_{2}$. Angew. Chem. Int. Ed., 2008, 47(24): 4516-4520.

[21] LEE J, MUBEEN S, JI X, et al. Plasmonic photoanodes for solar water splitting with visible light. Nano. Lett., 2012, 12(9): 5014-5019.

[22] MUBEEN S, LEE J, SINGH N, et al. An autonomous photosynthetic device in which all charge carriers derive from surface plasmons. Nat. Nanotechnol., 2013, 8(18): 247-251. 


\title{
碳一银共修饰的双晶介孔二氧化钛及其可见光催化活性
}

\author{
陆 强 ${ }^{1}$, 张智博 ${ }^{1}$, 董长青 ${ }^{1}$, 张晓媛 ${ }^{2}$, 崔方明 ${ }^{2}$
}

(1. 华北电力大学 生物质发电成套设备国家工程实验室, 北京 102206; 2. 中国空间技术研究院 钱学森空间技术实验 室, 北京 100094)

摘 要: 实验合成了一种具有锐钛矿和金红石双晶相骨架的介孔二氧化钛 $\left(m e s o-\mathrm{TiO}_{2}\right)$, 通过碳和银纳米粒子修饰分别 制备了碳掺杂 $\left(\mathrm{C}-\mathrm{meso}-\mathrm{TiO}_{2}\right)$ 、银纳米颗粒负载 $\left(\mathrm{Ag}-\mathrm{meso}-\mathrm{TiO}_{2}\right)$ 以及碳和银共修饰 $\left(\mathrm{Ag}-\mathrm{C}-\mathrm{meso}-\mathrm{TiO}_{2}\right)$ 的双晶介孔二氧化 钛, 然后通过其在可见光(波长 $>420 \mathrm{~nm}$ )下的亚甲基蓝(MB)水溶液的降解实验测试了样品的可见光催化活性。实验结 果显示 4 种双晶介孔材料的可见光催化活性均明显优于商业锐钛矿二氧化钛纳米颗粒。由于杂质碳的带隙窄化作用 和银纳米颗粒的表面等离子共振造成的电子转移, Ag-C-meso- $\mathrm{TiO}_{2}$ 展现出最优的可见光催化活性, 在 $180 \mathrm{~min}$ 可见光 照射后, 其 MB 降解率达到 $65 \%$, 而同样条件下商业二氧化钛纳米粒子的 MB 降解率仅为 7\%。

关 键 词: 可见光; 光催化活性; 双晶; 介孔二氧化钛; 银; 碳 中图分类号: O644

文献标识码: A 